J. Lake Sci. (湖泊科学), 2020, 32(2): 450-461

DOI 10. 18307/2020. 0214

(c) 2020 by Journal of Lake Sciences

\title{
冻融期包头南海湖浮游植物群落及优势种生态特征”
}

\author{
杨文焕, 申 涵, 周明利, 王志超, 李卫平**, 潘 形 \\ (内蒙古科技大学能源与环境学院,包头 014010)
}

\begin{abstract}
摘 要: 为了探究包头南海湖浮游植物群落特征和物种与生境之间的关系, 于 2018 年 11 月和 2019 年 1 月、 3 月分别对 南海湖浮游植物群落结构进行调查分析, 得出南海湖冻融期浮游植物群落结构为绿藻一硅藻一蓝澡型. 使用改进的 Levins 公式和 Petraitis 指数测定了南海湖冻融期优势种的生态位量度. 结果显示: 在不同生境条件下, 物种生态位宽度存在季节 性变化, 同样, 生态位重叠也随季节变化而变化. 随着湖面冰冻, 多数浮游植物生态位宽度有所下降; 结冰期生态位重叠 程度最高, 融冰期生态位重叠程度最低. 综合冻融过程优势藻种生态特征, 绿藻门的四尾栅藻 (Scenedesmus quadricauda) 是冻融过程中最主要优势种, 优势度、密度、生态位量度均优于其他优势澡种, 能充分利用环境资源, 更具竞争力. 优势种 与环境因子的灰关联分析显示, $\mathrm{pH}$ 是影响浮游植物优势种数量的主要相关因子.
\end{abstract}

关键词: 浮游植物; 冻融期; 优势种; 生态位;灰关联分析;包头南海湖

\section{Ecological characteristics of dominant phytoplankton community in Lake Nanhai (Baotou) during freezing-thawing period*}

\author{
YANG Wenhuan, SHEN Han, ZHOU Mingli, WANG Zhichao, LI Weiping ${ }^{* *}$ \& PAN Tong \\ ( College of Energy and Environment, Inner Mongolia University of Science and Technology, Baotou 014010, P.R.China)
}

\begin{abstract}
This study investigated the phytoplankton community structure and their relationship with habitats in Lake Nanhai of Baotou city, based on the data from November 2018 and January and March 2019 respectively. It found that the phytoplankton community comprised of Chlorophyta-Bacillariophyta-Cyanophyta in the freezing-thawing period. The niche traits of the dominant species in the freezing-thawing period were determined by using the improved Levins Niche Breadth Index and Petraitis Index. Results showed that there were seasonal changes in the niche breadth of the species under different habitats. Similarly, the niche overlap also changed with the seasons, with highest values during the icing period and lowest during the ice-melting period. Scenedesmus quadricauda was the most dominant species in the process of freezing and thawing. It's dominance degree, density, niche breadth and niche overlap are superior to other dominant phytoplankton species, and it can make full use of environmental resources, and be more competitive. Grey correlation analysis between dominant species and environmental factors showed that $\mathrm{pH}$ was the main factor affecting the density of dominant species of phytoplankton.
\end{abstract}

Keywords: Phytoplankton; freezing-thawing period; dominant species; niche; grey correlation analysis; Lake Nanhai, Baotou

浮游植物作为水生态系统中的初级生产者, 其群落结构的变化会对水生态系统中的营养转化产生影 响, 在生物地球化学循环中发挥着重要作用 ${ }^{[1]}$. 在水生态系统中, 浮游植物的变化一直被认为是该系统营养 状况和环境质量的良好指标 ${ }^{[2]}$, 而浮游植物的生长和多样性受到季节生境变化的控制. 季节性冻融是北方 地区重要的气候特征, 每年一次的冻融循环过程可引起水体环境因子的季节性振荡 ${ }^{[3]}$, 这些也会影响当年 浮游植物的生理、生化和代谢过程及其演替规律. 在冻融过程中, 浮游植物的季节性演替可能反映了物理、 化学和生物强迫因素之间的协同作用 ${ }^{[4]}$. 如果一个或一组强迫因素占主导地位, 那么某个优势种就会占主

* 2019-07-08 收稿; 2019-08-31 收修改稿.

国家重点研发计划项目 (2019YFC0609204)、内蒙古科技创新引导项目 (KCBJ2018033) 和内蒙古自然科学基金项 目 (2018LH04002) 联合资助.

** 通信作者;E-mail:sjlwp@ 163.com. 
导地位, 随着环境条件的变化, 优势种的身份也会随之发生变化. 因此, 冻融循环是影响浮游植物生命力的 因素之一,也是影响中高纬度和高海拔地区水生态系统过程的重要生态现象 ${ }^{[5]}$.

生态位理论已广泛应用于解释物种群落结构的研究, 可以更好地理解冻融过程中浮游植物种属之间的 相互作用、分布等相关机制, 然而这些研究大多集中在常温条件下的陆生植物上 ${ }^{[6-7]}$, 很少有明确量化冻融 条件下浮游植物生态位参数的研究. 而目前冻融过程相关的研究多以土壤和地下水为主 ${ }^{[8-9]}$, 对冻融期湖泊 浮游植物变化的研究鲜有报道. 南海湖是包头市的城市湖泊, 其生态环境类型具有独特性, 属于典型的寒旱 区内陆湖泊 ${ }^{[10]}$. 因此, 本文以湖泊的冻融过程作为切人点, 从浮游植物生态位这一角度出发, 认识季节性冻 融作用对浮游植物群落结构变化的影响, 在一定程度上, 实现了浮游植物与南海湖生态系统响应关系在冰 封期和非冰封期研究的结合, 最终研究成果也可为高寒地区城市小型湖泊研究提供参考.

\section{1 材料及方法}

\section{1 研究区概况}

南海湖 ( $40^{\circ} 30^{\prime} 8^{\prime \prime} \sim 40^{\circ} 33^{\prime} 32^{\prime \prime} \mathrm{N}, 109^{\circ} 59^{\prime} 26^{\prime \prime} \sim 110^{\circ} 2^{\prime} 26^{\prime \prime} \mathrm{E}$ ) 地处半干旱草原地区, 属半干旱温带大陆性气 候, 湖区面积 $333 \times 10^{4} \mathrm{~m}^{2}$, 最大水深达到 $3 \mathrm{~m}$. 夏季短暂而温暖, 冬季较为寒冷 ${ }^{[11]}$. 南海湖湖面每年冬天完全 结冰, 冰层厚度可达 $30 \sim 40 \mathrm{~cm}$. 融冰通常发生在 3 月份,之后地表水温度逐渐升高.

\section{2 采样点设置与采样时间}

结合南海湖水文水质特点和现场勘查情况, 在湖区自西向东共设 12 个采样点, 样点分布示意图见图 1 . 其中 1 号点位于引人黄河水的人水口附近, 由黄河定期对湖泊进行补水. 7 号点、9 号点位于湖心区域. 6 号 点位于排污口附近. 12 号点靠近芦苇区, 湖畔四周分布着茂密芦苇丛. 湖泊水样的采集于 2018 年 11 月(结 冰初期) 以及 2019 年 1 月 (结冰期) 和 3 月 (融冰期) 每月中旬进行.

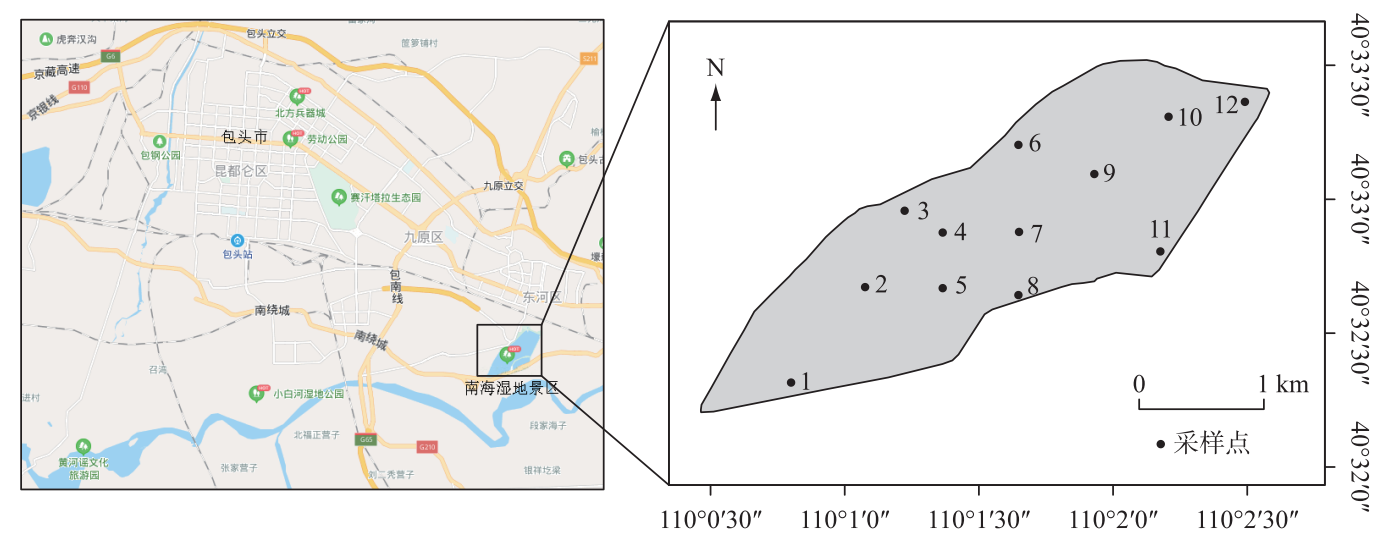

图 1 南海湖浮游植物采样点分布

Fig. 1 Distribution of phytoplankton sampling sites in Lake Nanhai

\section{3 样品采集与处理}

结冰期湖泊水体表面覆盖冰层, 采样时开丵冰洞, 取冰下水样. 其中浮游植物定量样品是采集表层水深 $0.5 \mathrm{~m}$ 处水样 $1 \mathrm{~L}$, 用鲁格溶液固定水样进行定量分析. 将浮游植物样品放人实验室静置 $48 \mathrm{~h}$, 利用虹吸法将 每个样品浓缩至 $50 \mathrm{~mL}$, 轻轻混合沉降后的样品, 取 $100 \mu \mathrm{L}$ 混匀样品转移到载玻片上, 在 $40 \times 10$ 倍标准光学 显微镜下鉴定优势种并对单个样品 50 个视野进行计数. 浮游植物种类鉴定参照《环境微生物图谱》及《淡水 型微生物图谱》等 ${ }^{[12-13]}$ 的方法.

同步采集水样测水质. 现场测定表层水 $(0.5 \mathrm{~m})$ 的水温 $(\mathrm{T}) 、 \mathrm{pH}$ 、溶解氧 $(\mathrm{DO})$ 等指标; 总氮 $(\mathrm{TN})$ 、氨氮 $\left(\mathrm{NH}_{3}-\mathrm{N}\right)$ 、总磷 $(\mathrm{TP})$ 和化学需氧量 $(\mathrm{COD})$ 等理化指标的测定分析方法均按照《水和废水监测分析方法》 ${ }^{[14]}$ 进行测定. 


\section{4 数据分析}

1) 优势种以优势度指数 $Y \geqslant 0.02$ 确定, 优势度指数 ${ }^{[15]}$ 的计算公式如下:

$$
Y=\frac{n_{i}}{N} f_{i}
$$

式中, $n_{i}$ 为样点中第 $i$ 种浮游植物的个体数: $N$ 为样点中所有浮游植物的总数: $f_{i}$ 为该种属在各样点中出现 的频率.

2) 利用 Shannon-Wiener 指数 $\left(H^{\prime}\right)$ 、Pielou 均匀度指数 $(J)$ 以及 Margalef 丰富度指数 $(D)$ 对浮游植物群 落多样性进行分析 ${ }^{[16]}$, 计算公式如下:

$$
\begin{gathered}
H^{\prime}=-\sum\left(n_{i} / N\right) \ln \left(n_{i} / N\right) \\
J=H^{\prime} / \log _{2} S \\
D=(S-1) / \ln N
\end{gathered}
$$

式中, $S$ 为样品中浮游植物种类数.

3) 对生态位宽度的标准化度量采用修正后的 Levins 指数 ${ }^{[17]}$, 计算公式如下:

$$
B_{i}=1 /\left(r \sum_{j=1}^{r} P_{i j}\right)^{2}
$$

式中, $B_{i}$ 为种 $i$ 的生态位宽度; $P_{i j}=n_{i j} / N_{i}$, 代表种 $i$ 在第 $j$ 个资源状态下的个体数占该种所有个体数的比 例; $r$ 为样点数.

4) 对生态位重叠的标准化度量采用 Petraitis 指数 ${ }^{[18]}$, 计算公式如下:

$$
\begin{gathered}
S O_{i k}=\mathrm{e}^{E_{i k}} \\
E_{i k}=\sum_{j=1}^{r}\left(P_{i j} \ln P_{k j}\right)-\sum_{j=1}^{r}\left(P_{i j} \ln P_{i j}\right) \\
\Delta S O_{i j}=\sum_{j=1}^{n} S O_{i j}-\sum_{i=1}^{m} S O_{i j} \\
R_{i}=\frac{B_{i}}{\Delta S O_{i j}}
\end{gathered}
$$

式中, $S O$ 为成对种间生态位特定重叠; $k$ 为不同于 $i$ 的另一种浮游植物; $\sum_{j=1}^{n} S O_{i j}$ 表明种 $i$ 占用其他种的资 源量; $\sum_{i=1}^{m} S O_{i j}$ 表明种 $j$ 被其他种侵占的资源量; $R_{i}$ 为生态响应速率.

$5)$ 灰色关联分析法 ${ }^{[19]}$ 用于评判环境因子对浮游植物数量的影响强弱. 为了消除在灰关联分析中不同 量纲所带来的影响, 通过均值法对原始数据进行无量纲处理, 在 DPS 软件上进行具体操作.

\section{2 结果与分析}

\section{1 浮游植物群落结构特征}

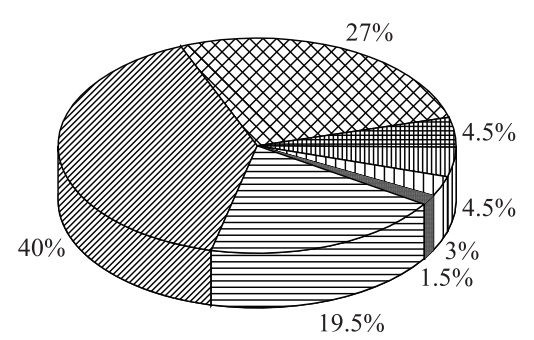

图 2 南海湖浮游植物种类组成比例

Fig.2 Proportion of phytoplankton species in Lake Nanhai
2.1.1 浮游植物种类组成 浮游植物的种类组成和 数量主要受特定环境的理化参数影响. 调查期间共 鉴定出浮游植物 7 门 57 属 67 种. 其中绿藻门种类 最多, 有 24 属、 27 种, 占种类总数的 $40 \%$; 硅藻门 14 属、18 种, 占 $27 \%$; 蓝藻门 12 属、 13 种, 占 $19.5 \%$, 三 者共占总种数的 $86.5 \%$; 金藻门和黄藻门均为 2 属、 3 种, 共占 $9 \%$; 隐藻门 2 属 2 种, 占 3\%; 裸藻门最 少, 只有 1 属、 1 种, 占 $1.5 \%$ (图 2). 由图 3 可知, 从 时间维度上看, 南海湖浮游植物种数结冰初期和融 冰期种类数量并无太大差异. 随着温度的降低, 结冰 期种类数较其他两个时期有所减少; 在空间维度上, 
物种数的多少主要取决于采样点位周边环境条件, 在湖区由西往东有逐渐增加的趋势. 其中靠近芦苇区的 12 号采样点浮游植物种类最多; 其次是湖心处的 7 号和 9 号采样点; 排污口处 6 号采样点种类最少.
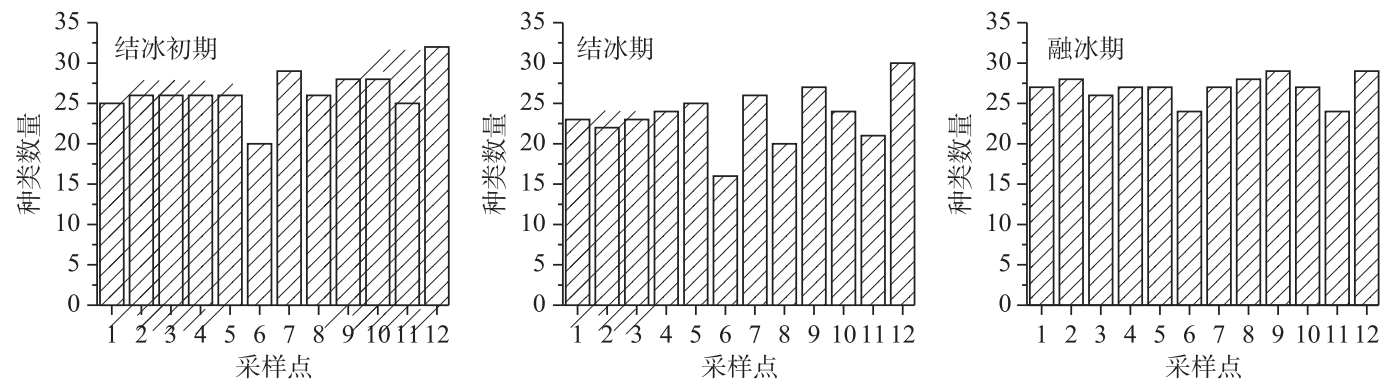

图 3 南海湖浮游植物种类数的时空变化

Fig. 3 Temporal and spatial changes of the phytoplankton species number of Lake Nanhai

2.1.2 浮游植物密度 研究期间浮游植物细胞密度变化范围为 $5.60 \times 10^{6} \sim 18.90 \times 10^{6}$ cells $/ \mathrm{L}$. 细胞密度居于 前 3 位的依次为绿藻门、蓝藻门、硅藻门. 其中绿藻门密度占总密度的 $55.60 \%$, 蓝藻门占 $31.78 \%$, 硅藻门占 $10.80 \%$. 从图 4 可以看出, 就南海湖整体而言, 在整个冻融期间内其浮游植物的密度空间分布不均匀, 其趋 势是湖区边缘向湖心区域逐渐递增, 且湖心处整体密度较高, 峰值出现在 7 号点和 9 号点. 密度最低点出现 在排污口附近的 6 号点, 此外靠近芦苇区的 12 号点处密度较低, 其它监测点的细胞密度无显著差异. 从图 5 看出, 由于湖泊表层形成冰盖导致湖泊内部理化条件发生变化, 同时水体自净能力差, 影响了浮游植物细胞 密度, 而采样点之间密度也有所差异. 结冰初期细胞整体密度普遍较高, 结冰期整体密度最低, 融冰期随着 温度升高, 细胞密度逐渐有所回升. 且在冻融期间, 结冰初期和结冰期绿藻门密度最高, 分别占浮游植物总 密度的 50.73\% 和 62.96\%. 融冰期则蓝藻门密度增加, 在部分点位密度高于绿藻门.

2.1.3 浮游植物群落多样性 南海湖冻融期浮游植物 Shannon-Wiener 指数在 $1.44 \sim 2.65$ 之间波动, 平均值为 1.91 ; Pielou 均匀度指数在 $0.31 \sim 0.53$ 之间波动, 平均值为 0.41 ; Margalef 丰富度指数在 $1.39 \sim 2.57$ 之间波动,平 均值为 1.97. 多样性指数变化趋势基本一致,结冰期最低,与浮游植物种类数变化趋势基本呈对应关系 (图 6).

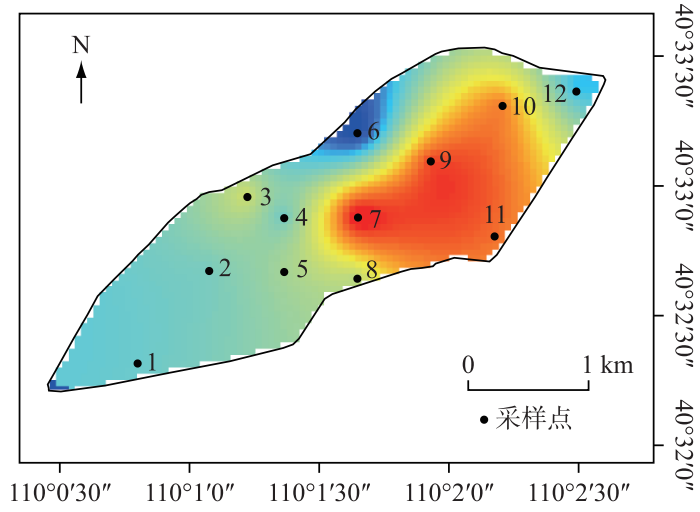

图 4 南海湖冻融期浮游植物密度空间分布

Fig.4 The spatial distribution of phytoplankton density during the freezing-thawing period of Lake Nanhai

\section{2 浮游植物优势种}

根据优势度计算结果 $(Y \geqslant 0.02)$, 调查期间全湖共鉴定优势种 3 门 11 种 (表 1$)$, 主要为蓝藻门的水华束 丝藻、微小色球藻、微小平裂藻、高山立方藻、石生蓝纤维藻; 绿藻门的四尾栅藻、镰形纤维藻、球衣藻、螺旋 弓形藻; 硅藻门的克洛脆杆藻、普通等片藻. 

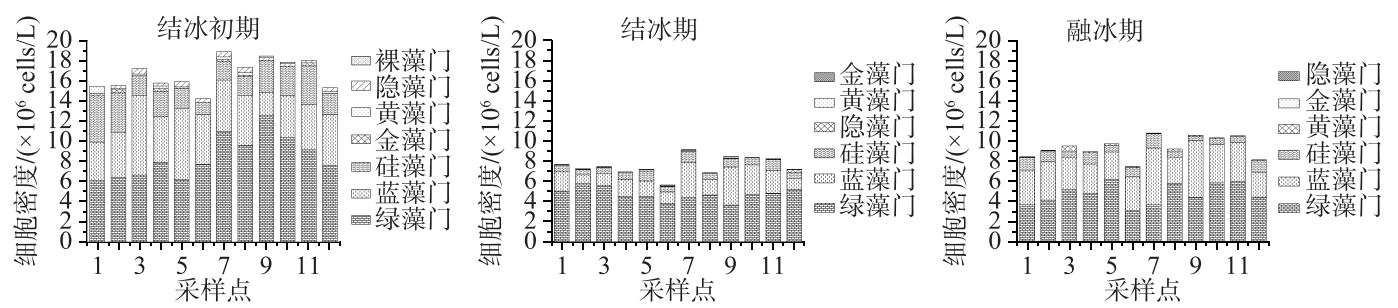

图 5 南海湖不同时期浮游植物密度分布

Fig.5 Phytoplankton density distribution in different periods of Lake Nanhai
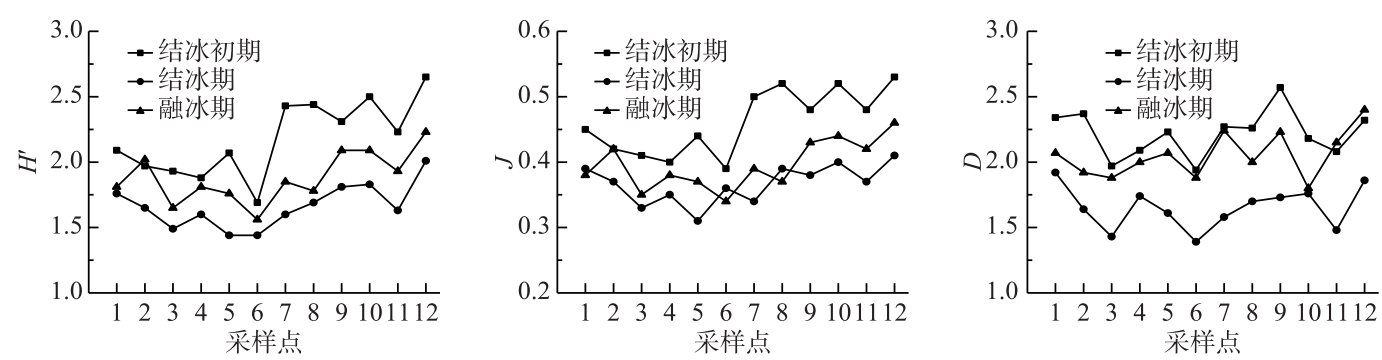

图 6 南海湖浮游植物群落多样性指数分布

Fig.6 Diversity index distribution of phytoplankton community in Lake Nanhai

优势种种类在不同月份既有重叠又有演替, 优势种的优势度和密度在不同时期均有所不同 (表 2). 南 海湖冻融过程中优势种以蓝藻门和绿藻门的种类为主, 微小平裂藻、水华束丝藻、四尾栅澡、螺旋弓形藻和 普通等片藻在整个冻融过程中均为优势种. 绿藻门的四尾栅藻在整个冻融期间数量都较多, 在结冰初期和 融冰期的优势度指数为相应时期的最大值, 且远大于其他优势种的优势度指数, 为全湖优势度较高的主要 优势种. 结冰期浮游植物优势种以绿藻门种类居多; 结冰期新出现的石生蓝纤维藻替代了同为蓝藻门的微 小色球藻, 绿藻门新出现了镰形纤维藻和球衣藻, 且镰形纤维藻的优势度和密度在结冰期最高, 球衣藻仅次 于它; 融冰期的优势种种类组成与结冰期较为相似, 在此期间蓝藻门的微小平裂藻优势度和密度都有显著 上升, 此外新出现了同为蓝藻门的高山立方藻, 但优势度不高. 整个冻融期间硅藻门的浮游植物优势种优势 度和密度均较低.

表 1 南海湖冻融期优势种名录

Tab.1 Dominant species of phytoplankton in Lake Nanhai

\begin{tabular}{|c|c|c|c|c|}
\hline 门 & 种类 & 结冰初期 & 结冰期 & 融冰期 \\
\hline 蓝藻门 & 微小平裂藻 (Merismopedia tenuissima) & $*$ & $*$ & $*$ \\
\hline \multirow[t]{4}{*}{ ( Cyanophyta) } & 微小色球藻 ( Chroococcus limneticus) & * & - & - \\
\hline & 水华束丝藻( Aphanizomenon flosaquae) & * & * & * \\
\hline & 石生蓝纤维藻 (Dactylococcopsis rupestris) & - & $*$ & - \\
\hline & 高山立方藻( Eucapsis alpina) & - & - & * \\
\hline 绿藻门 & 镰形纤维藻 (Ankistrodesmus falcatus) & - & $*$ & * \\
\hline \multirow[t]{3}{*}{ ( Chlorophyta) } & 球衣藻( Chlamydomonas globosa) & - & $*$ & - \\
\hline & 四尾栅藻 ( Scenedesmus quadricauda) & $*$ & $*$ & * \\
\hline & 螺旋弓形藻 ( Schroederia spiralis) & * & $*$ & $*$ \\
\hline 硅藻门 & 普通等片藻( Diatoma vulgare) & $*$ & $*$ & $*$ \\
\hline (Bacillariophyta) & 克洛脆杆藻 (Fragilaria crotomensis) & * & - & - \\
\hline
\end{tabular}

“*”表示该藻种在当季出现, “一”表示该藻种在当季并不出现. 


\section{3 浮游植物优势种生态位宽度}

生态位宽度是指种群在生长过程中综合利用的不同资源的总和或对资源利用的多样化程度,其值大小 较好地反映了物种的分布、种群的生态适应性和资源利用的潜在能力 ${ }^{[20]}$. 在同一生境中一个物种的生态位 越宽,就有较强的利用不同资源的能力,在种间资源竞争中处于强势.

使用经过加权修改的 Levins 公式计算冻融期间的优势种生态位宽度如表 2 所示. 结冰初期浮游植物优 势种的生态位宽度为 $0.408 \sim 0.909$, 湖泊水体中浮游植物优势种的生态位宽度总体较高, 表明大多数藻类种 属对此期间湖泊水体的环境条件具有较好的适应性,生态适应幅度较广. 除了蓝藻门的微小平裂藻、硅藻门 的克洛脆杆藻之外, 其余优势种生态位宽度值均在 0.7 以上. 尤其是绿藻门的螺旋弓形藻、四尾栅藻以及蓝 藻门的水华束丝藻, 物种优势度均在 0.1 以上, 生态位宽度值也均 $>0.7$, 说明它们在结冰初期对环境的适应 能力强, 利用资源能力高. 此外硅藻门的普通等片藻尽管密度不大, 但由于在各样点间密度分布更为均匀使 得其生态位仅次于水华束丝藻.

结冰期浮游植物优势种生态位宽度为 $0.301 \sim 0.655$,与结冰初期相比,多数藻类种属生态位宽度值下降. 其中只有四尾栅藻、水华束丝藻和石生蓝纤维藻的生态位宽度较宽 (均>0.6), 表明大多数藻类优势种对湖 泊水体内环境适应能力弱,生态适应幅度较小, 而四尾栅藻、水华束丝藻、石生蓝纤维藻在结冰期的环境资 源利用充分, 具有较强的竞争能力. 此外在此期间内新出现的绿藻门的镰形纤维藻和球衣藻尽管密度较高, 但因在各样点间密度分布不均匀,使得生态位值均较小.

融冰期浮游植物优势种生态位宽度为 $0.453 \sim 0.853$,相较于结冰期,除水华束丝藻生态位宽度值下降 外, 多数种属生态位宽度值增大, 表明多数种属生态适应性均有增强. 其中四尾栅藻、螺旋弓形藻、镰形纤维 藻的生态位宽度均 $>0.8$, 只有高山立方藻生态位宽度值小于 0.5 , 说明在融冰期高山立方藻对环境因子有一 定的依赖性, 只在环境较为适合的时期出现, 对环境适应性较弱而无法充分地利用生境资源. 相对而言, 微 小平裂藻、水华束丝藻、四尾栅藻、螺旋弓形藻和普通等片藻在冻融过程中分布较为广泛. 各优势藻的生态 位宽度反映了其数量以及在不同资源点位的分布状况. 湖泊水体的生境条件会由于季节性冻融而发生变 迁, 影响藻类生长繁殖, 从而导致各优势种在不同时期有不同的生态位宽度值.

$$
\text { 表 } 2 \text { 南海湖浮游植物优势种密度 }\left(D, \times 10^{7} \text { cells } / \mathrm{L}\right) \text { 、优势度 }(Y) \text { 及生态位宽度 }\left(B_{i}\right)
$$

Tab.2 Density $(D)$, dominance $(Y)$ and niche breadth $\left(B_{i}\right)$ of dominant phytoplankton species in Lake Nanhai

\begin{tabular}{|c|c|c|c|c|c|c|c|c|c|}
\hline \multirow{2}{*}{ 优势种 } & \multicolumn{3}{|c|}{ 结冰初期 } & \multicolumn{3}{|c|}{ 结冰期 } & \multicolumn{3}{|c|}{ 融冰期 } \\
\hline & $Y$ & $D$ & $B_{i}$ & $Y$ & $D$ & $B_{i}$ & $Y$ & $D$ & $B_{i}$ \\
\hline 微小平裂藻 & 0.028 & 1.33 & 0.408 & 0.024 & 0.48 & 0.301 & 0.184 & 2.05 & 0.763 \\
\hline 微小色球藻 & 0.107 & 2.29 & 0.722 & - & - & - & - & - & - \\
\hline 水华束丝藻 & 0.067 & 1.31 & 0.909 & 0.020 & 0.22 & 0.640 & 0.041 & 0.55 & 0.614 \\
\hline 石生蓝纤维藻 & - & - & - & 0.075 & 0.75 & 0.649 & - & - & - \\
\hline 高山立方藻 & - & - & - & - & - & - & 0.055 & 1.23 & 0.453 \\
\hline 镰形纤维藻 & - & - & - & 0.224 & 3.03 & 0.478 & 0.113 & 1.27 & 0.853 \\
\hline 球衣藻 & - & - & - & 0.114 & 1.60 & 0.365 & - & - & - \\
\hline 四尾栅藻 & 0.121 & 2.37 & 0.728 & 0.083 & 0.77 & 0.655 & 0.274 & 3.06 & 0.843 \\
\hline 螺旋弓形藻 & 0.101 & 1.97 & 0.751 & 0.021 & 0.23 & 0.518 & 0.046 & 0.51 & 0.803 \\
\hline 普通等片藻 & 0.065 & 1.28 & 0.885 & 0.021 & 0.24 & 0.502 & 0.033 & 0.37 & 0.715 \\
\hline 克洛脆杆藻 & 0.031 & 0.72 & 0.608 & - & - & - & - & - & - \\
\hline
\end{tabular}

“一”表示该藻种在当季并不出现.

\section{4 浮游植物优势种生态位重叠}

在种属间生态位重叠方阵中, $S O_{i j}$ 是种 $i$ 占用种 $j$ 资源的大小,或者说种 $j$ 被种 $i$ 侵占的资源量. 当 $i=j$ 时, 通过比较 $\Delta S O_{i j}$ 大小来说明不同的环境条件下不同种属的生态习性变化和发展衰退状况. $\Delta S O_{i j}$ 为正值 时,表明该种属处于发展状态, 为负值时则为衰退状态, 为 0 时则表明该种属为中性种, 差值的大小反映了 
该种发展或衰退的数值变化 ${ }^{[21]}$. 为了更准确地确定不同时期优势种对生境条件的生态响应, 本文结合生态 位宽度计算了生态响应速率 $R$,计算结果如表 3 所示.

结冰初期, 微小平裂藻有最大的负 $\Delta S O_{i j}$, 表明该种衰退空间最大, 克洛脆杆藻同属于衰退型, 生长空间 同呈缩小趋势; 其余优势种均处于发展型, 其中螺旋弓形藻有最大的正 $\Delta S O_{i j}$. 结冰期, 微小平裂藻和球衣藻 属于衰退型, 其余各优势种处于发展型, 四尾栅藻有最大的发展空间, 均大于其他季节的优势种, $\Delta S O_{i j}$ 是 3 个时期的最大值. 石生蓝纤维藻发展空间略小于四尾栅藻, 其他发展型藻类发展空间缩小. 融冰期, 微小平 裂藻、镰形纤维藻、四尾栅藻和普通等片藻同属于发展型且发展空间处于同一水平, 发展空间略大于螺旋弓 形藻, 且微小平裂藻较前两个时期发展空间增大明显, 由衰退型物种转变为发展型物种. 此外四尾栅藻有最 大的发展空间,而高山立方藻和水华束丝藻属于衰退型.

就冻融过程来看, 微小平裂藻与其他优势种之间的生态位重叠程度 ( $\Delta S O_{i j}$ 的绝对值) 最大, 且蓝藻门各 优势种与其他藻类之间的生态位重叠程度相对偏高. 从不同时期看, 融冰期各优势种的生态位重叠值均较 低, 以高山立方藻与其他优势种的生态位重叠程度最高, 而结冰初期和结冰期以微小平裂藻的生态位重叠 值为最高.

表 3 南海湖浮游植物优势种生态位重叠 $\left(\Delta S O_{i j}\right)$ 和生态响应速率 $(R)$

Tab.3 Niche overlap $\left(\Delta S O_{i j}\right)$ and ecological response rate $(R)$ of dominant phytoplankton species in Lake Nanhai

\begin{tabular}{|c|c|c|c|c|c|c|}
\hline \multirow{2}{*}{ 优势种 } & \multicolumn{2}{|c|}{ 结冰初期 } & \multicolumn{2}{|c|}{ 结冰期 } & \multicolumn{2}{|c|}{ 融冰期 } \\
\hline & $\Delta S O_{i j}$ & $R$ & $\Delta S O_{i j}$ & $R$ & $\Delta S O_{i j}$ & $R$ \\
\hline 微小平裂藻 & -24.395 & -0.017 & -31.028 & -0.010 & 2.752 & 0.277 \\
\hline 微小色球藻 & 4.247 & 0.170 & - & - & - & - \\
\hline 水华束丝藻 & 5.635 & 0.161 & 5.406 & 0.118 & -2.248 & -0.273 \\
\hline 石生蓝纤维藻 & - & - & 10.917 & 0.059 & - & - \\
\hline 高山立方藻 & - & - & - & - & -11.580 & -0.039 \\
\hline 镰形纤维藻 & - & - & 0.748 & 0.639 & 2.816 & 0.303 \\
\hline 球衣藻 & - & - & -3.963 & -0.092 & - & - \\
\hline 四尾栅藻 & 4.906 & 0.148 & 11.020 & 0.059 & 3.230 & 0.261 \\
\hline 螺旋弓形藻 & 6.129 & 0.122 & 5.751 & 0.090 & 2.000 & 0.401 \\
\hline 普通等片藻 & 5.784 & 0.153 & 1.149 & 0.437 & 3.030 & 0.236 \\
\hline 克洛脆杆藻 & -2.306 & -0.263 & - & - & - & - \\
\hline
\end{tabular}

“一”表示该藻种在当季并不出现.

表 4 南海湖冻融期水体理化指标

Tab.4 Physical and chemical parameters during freezing-thawing period in Lake Nanhai

\begin{tabular}{cccc}
\hline 环境因子 & 结冰初期 & 结冰期 & 融冰期 \\
\hline $\mathrm{T} /{ }^{\circ} \mathrm{C}$ & $2.27 \pm 0.79$ & $2.15 \pm 0.52$ & $8.74 \pm 2.01$ \\
$\mathrm{DO} /(\mathrm{mg} / \mathrm{L})$ & $6.18 \pm 0.93$ & $4.44 \pm 0.67$ & $4.06 \pm 1.44$ \\
$\mathrm{pH}$ & $8.53 \pm 0.11$ & $8.67 \pm 0.09$ & $8.35 \pm 0.16$ \\
$\mathrm{TN} /(\mathrm{mg} / \mathrm{L})$ & $4.22 \pm 0.76$ & $5.26 \pm 0.57$ & $4.66 \pm 0.37$ \\
$\mathrm{NH}_{3}-\mathrm{N} /(\mathrm{mg} / \mathrm{L})$ & $1.80 \pm 0.49$ & $2.17 \pm 0.37$ & $1.45 \pm 0.17$ \\
$\mathrm{TP} /(\mathrm{mg} / \mathrm{L})$ & $0.67 \pm 0.16$ & $0.45 \pm 0.11$ & $0.28 \pm 0.10$ \\
$\mathrm{COD}_{\mathrm{Cr}} /(\mathrm{mg} / \mathrm{L})$ & $159.20 \pm 28.01$ & $183.60 \pm 33.16$ & $106.67 \pm 22.44$ \\
\hline
\end{tabular}

\section{5 浮游植物优势种与环境因子的灰关联分析}

灰关联分析 (Grey correlation analysis) ${ }^{[19]}$ 是 对灰色系统发展趋势进行定量描述和比较, 它基 于空间理论且根据规范性、偶对称性、整体性和 接近性的原则, 通过确定参考序列和若干比较序 列之间的灰色关系, 进一步评估每个比较序列对 参考序列的相对重要程度, 从而得出各因素之间 的相关性. 此方法的主要理论是根据不同数据序 列的几何形状相似性来判断其关联度. 不同数据 序列的关联度越大, 其几何形状越相似, 反之则 越小. 因此, 通过灰关联分析, 可以揭示各个环境 因子对南海湖浮游植物群落数量的影响强弱.

确定参考数据序列和比较数据序列, 选择浮游植物优势种数量作为参考数据序列 $\left\{\mathrm{X}_{0}\right\}$, 并选用 $\mathrm{T}\left\{\mathrm{X}_{1}\right\}$ 、 $\mathrm{DO}\left\{\mathrm{X}_{2}\right\} 、 \mathrm{pH}\left\{\mathrm{X}_{3}\right\} 、 \mathrm{TN}\left\{\mathrm{X}_{4}\right\} 、 \mathrm{NH}_{3}-\mathrm{N}\left\{\mathrm{X}_{5}\right\} 、 \mathrm{TP}\left\{\mathrm{X}_{6}\right\} 、 \mathrm{COD}_{\mathrm{Cr}_{\mathrm{r}}}\left\{\mathrm{X}_{7}\right\}$ 作为比较数据序列进行灰关联分析. 数据利 
用均值法进行归一化处理, 以便进行比较. 在灰色关联分析中,因子的重要性用关联度表示, 关联度越大,则 表示因子越重要. 为了分析南海湖浮游植物优势种数量的影响因素, 采用灰关联分析处理各影响因素 (表 4) 与浮游植物优势种数量之间的相关分析结果如表 5 所示.

由表 5 可以看出, 结冰初期对南海湖浮游植物优势种数量产生影响的主要相关因子为 $\mathrm{TP} 、 \mathrm{pH}$ 和 $\mathrm{COD}_{\mathrm{Cr}}$, 结冰期对南海湖浮游植物优势种数量产生影响的主要相关因子是 $\mathrm{pH} 、 \mathrm{DO}$ 和 $\mathrm{COD}_{\mathrm{Cr}}$, 融冰期对南海湖 浮游植物优势种数量产生影响的主要相关因子是 $\mathrm{pH} 、 \mathrm{NH}_{3}-\mathrm{N}$ 和 T. 可见不同时期对浮游植物优势种数量产 生影响的主要相关因子并不相同, 其中影响最大的是 $\mathrm{pH}$, 在 3 个时期它均与南海湖浮游植物优势种数量有 高关联度. 因此, 冻融期浮游植物优势种数量的变化与 $\mathrm{pH}$ 的变化有着密切联系.

表 5 南海湖冻融期浮游植物优势种与环境因子关联度及排序

Tab.5 Effect of environment factors on the relational degree and sorting of phytoplankton dominant species' density during freezing-thawing period in Lake Nanhai

\begin{tabular}{|c|c|c|c|c|c|c|}
\hline \multirow{2}{*}{ 环境因子 } & \multicolumn{2}{|c|}{ 结冰初期 } & \multicolumn{2}{|c|}{ 结冰期 } & \multicolumn{2}{|c|}{ 融冰期 } \\
\hline & 关联度 & 排序 & 关联度 & 排序 & 关联度 & 排序 \\
\hline $\mathrm{T}$ & 0.6546 & 4 & 0.6735 & 6 & 0.6631 & 3 \\
\hline DO & 0.6412 & 6 & 0.7237 & 2 & 0.6298 & 6 \\
\hline $\mathrm{pH}$ & 0.6892 & 2 & 0.7908 & 1 & 0.7003 & 1 \\
\hline $\mathrm{TN}$ & 0.6504 & 5 & 0.6968 & 4 & 0.6614 & 4 \\
\hline $\mathrm{NH}_{3}-\mathrm{N}$ & 0.6377 & 7 & 0.6816 & 5 & 0.6791 & 2 \\
\hline TP & 0.6909 & 1 & 0.6352 & 7 & 0.5705 & 7 \\
\hline $\mathrm{COD}_{\mathrm{Cr}}$ & 0.6732 & 3 & 0.7119 & 3 & 0.6479 & 5 \\
\hline
\end{tabular}

\section{3 讨论}

\section{1 浮游植物优势种生态位}

生态位宽度通过反映种群对资源水平变化的耐受性、抵御竞争者的能力进而反映物种在生境中的分布 状况, 其值的大小主要用来解释环境变化如何是影响物种的分布和数量 ${ }^{[22]}$. 综合各门藻类生态特征统计结 果, 结冰初期与融冰期湖泊水体内均以绿藻门的四尾栅藻密度最大, 且在结冰期其生态位宽度最大. 这是由 于四尾栅藻温度适应性强, 即使在结冰期四尾栅藻虽然密度不是最大, 但在各个监测点间分布广、占据资源 点位多, 适应多样化生境的资源的能力强. 物种的生态位越宽, 其利用资源的能力和多样化程度越高; 在结 冰初期, 水华束丝藻、螺旋弓形藻以及普通等片藻相比四尾栅藻密度要低但在各样点间密度分布更为均匀, 从而使其相应生态位宽度值更大, 体现了这些藻种分布范围广, 竞争能力强, 可以充分利用环境资源来适应 不同生境. 极端的生境条件影响了某些藻种的生态位宽度,球衣藻和石生蓝纤维藻对生境的适应具有选择 性, 出现的时间相对集中且仅在满足结冰的环境条件下占显著优势. 由于其生态位较窄, 密度不大, 为了适 应这种严酷环境, 这些藻种通过扩展其生态位, 以增大其对资源利用的范围, 向最适资源水平位置集中来占 据资源优势. 在结冰初期均以主要优势种存在的微小色球藻和螺旋弓形藻, 由于其特化程度较高, 在生境中 某些因素对其生长或分布起限制作用, 导致到了结冰期时生态位宽度值明显变窄, 且微小色球藻在此时已 不是优势种. 生境条件的变迁也会影响各优势种的分布情况, 导致它们的生态位宽度发生变化; 在融冰期 时, 作为在整个冻融过程中均以主要优势种存在的水华束丝藻, 生态位宽度明显低于其他优势种. 总而言 之, 随着湖泊湖面冻结, 温度降低, 绿藻门逐渐成为主要优势种, 生态位宽度值较大, 均属于发展型优势种; 结冰后湖泊内水体流速减小交换迟缓, 藻类以绿藻为主, 四尾栅藻等种群发展呈扩张状态. 而硅藻受到冰封 期湖泊环境影响, 其自身细胞结构受限 ${ }^{[23]}$, 无法有效吸收营养物质, 不能大量生长; 融冰时, 在适宜的水温下 藻类大量繁殖, 尤以微小平裂藻数量增长明显, 生态位宽度变大且属于发展型优势种. 对于整个冻融过程中 均是优势种的藻属, 只有水华束丝藻优势度和生态位宽度较前两个时期都有明显降低, 这可能是在此时期 与其它水生植物竞争抑制了本身的繁殖生长或是相应较宽生态位的藻种此时分泌的化感物质通过破坏它 
的细胞结构,减少藻类的同化产物 ${ }^{[24]}$,对其产生了强大的竞争压力,影响了它对资源的利用.

生态位重叠体现了生态群落中的物种分配可利用资源的方式和适应不同生境能力的相似程度, 因此它 被认为是群落物种多样性的主要决定因素 ${ }^{[25-26]}$. 通过计算不同物种生态位重叠指数, 发现在一定环境范围 内,生态位重叠值更大的物种将会利用更多环境资源. 物种可能会随着时间的推移而适应不断变化的环境 条件,当环境资源发生变化时会提高物种间利用资源的竞争力,这种复杂的变化使得不同种属之间的重叠 状态也会发生变化. 在结冰初期和结冰期湖泊内微小平裂藻与其他优势种属间的生态位重叠偏高, 生长空 间处于衰退状态, 说明优势种之间无论是种内还是种间在资源利用上都竞争激烈, 资源竞争过程中的生物 间的抑制作用会影响湖泊藻类群落结构和分布. 此外, 在不同生境条件下各常见种属生态位重叠值变化较 大. 如生境条件发生的变化导致了微小平裂藻的生态位重叠指数在结冰期和融冰期相差很大, 其分布情况 和占据的资源数量都产生了波动, 反映了湖泊水体在结冰时和融冰时浮游植物群落结构的变化. 在生物群 落中, 各物种的生态位总是倾向于分享其他物种的基础生态位部分, 引起多个物种对某些资源的共同需求, 使不同物种的生态位之间常处于不同程度的重叠状态 ${ }^{[27]}$. 在融冰期各优势种与其他优势种之间的生态位 重叠相对较低, 当种间竞争减少时, 一个物种内部的竞争就会成为一种强大的进化力量, 导致物种迅速出现 多样化, 反映了群落处于相对稳定的状态, 其种间关系协调, 能共同分享环境资源, 这与初春浮游植物群落 多样性较高的研究结果相一致 ${ }^{[28-29]}$.

两个具有宽生态位宽度的种群通常比具有窄生态位宽度的种群或一个种群具有宽生态位宽度和另一 个种群具有窄生态位宽度的种群具有更高的生态位重叠值. 将各时期优势种优势度 $(Y)$ 、密度 $(D)$ 、生态位 宽度 $\left(B_{i}\right)$ 和生态位重叠度 $\left(\Delta S O_{i j}\right.$ ) 进行相关性分析 (结果见表 6). 优势种密度与优势度在冻融过程中极显 著相关, 优势种生态位宽度与生态位重叠也呈极显著相关. 表明优势种的生态位与其优势地位、分布范围和 均匀程度都密切相关.

\section{2 浮游植物优势种生态特征与理化因子}

生境的变迁使得物种对环境的利用和适应能力发生变化, 进而导致生态位宽度和生态位重叠发生改变. 理化因子对浮游植物生长的生理特征和群落结构有着极其重要的影响 ${ }^{[30]}$. 通过对环境因子与优势种密度 进行灰关联分析, 结果显示此次调查中 $\mathrm{pH}$ 是影响浮游植物优势种分布的重要因子. 各种浮游植物的生长都 有一定的 $\mathrm{pH}$ 范围, 南海湖水体呈弱碱性 (表 4), 且整个湖体分布较为均匀, 对浮游植物的分布也有重要影 响. 水体中 $\mathrm{pH}$ 值主要受 $\mathrm{CO}_{2}$ 含量及 $\mathrm{HCO}_{3}^{-}$浓度的控制, 这是由于水体中藻类光合作用对 $\mathrm{CO}_{2}$ 的持续消耗的 累积效应造成的 ${ }^{[31]}$. $\mathrm{CO}_{2}$ 作为藻类的主要碳源而促进其光合作用, 藻类通过光合作用将 $\mathrm{CO}_{2}$ 等物质转化为 体内有机物, 不断生长繁殖. 但当水中 $\mathrm{H}^{+}$消耗较多时, $\mathrm{pH}$ 升高, 反过来浮游植物的光合作用将受到抑制, 所 以一般情况下, 弱碱性水体环境有利于浮游植物群落结构的发展 ${ }^{[32]}$. 本研究中, 在整个冻融过程中浮游植 物密度与 $\mathrm{pH}$ 的灰关联度一直排前 2 , 说明 $\mathrm{pH}$ 在这个过程中是浮游植物密度变化的主导因子.

表 6 优势度 $(Y)$ 、优势种密度 $(D)$ 、生态位宽度 $\left(B_{i}\right)$ 和生态位重叠 $\left(\Delta S O_{i j}\right)$ 的相关分析

Tab.6 Correlation analysis among dominance $(Y)$, density $(D)$, niche breadth $\left(B_{i}\right)$ and niche overlaps $\left(\Delta S O_{i j}\right)$

\begin{tabular}{|c|c|c|c|c|c|c|c|c|c|c|c|c|}
\hline & \multicolumn{4}{|c|}{ 结冰初期 } & \multicolumn{4}{|c|}{ 结冰期 } & \multicolumn{4}{|c|}{ 融冰期 } \\
\hline & $Y$ & $D$ & $B_{i}$ & $\Delta S O_{i j}$ & $Y$ & $D$ & $B_{i}$ & $\Delta S O_{i j}$ & $Y$ & $D$ & $B_{i}$ & $\Delta S O_{i j}$ \\
\hline$Y$ & 1 & $\begin{array}{c}0.920 \\
\left(0.003^{* *}\right)\end{array}$ & $\begin{array}{c}0.470 \\
(0.287)\end{array}$ & $\begin{array}{c}0.677 \\
(0.095)\end{array}$ & 1 & $\begin{array}{c}0.985 \\
\left(0.000^{* *}\right)\end{array}$ & $\begin{array}{c}-0.086 \\
(0.839)\end{array}$ & $\begin{array}{c}0.142 \\
(0.736)\end{array}$ & 1 & $\begin{array}{c}0.975 \\
\left(0.000^{* *}\right)\end{array}$ & $\begin{array}{c}0.518 \\
(0.234)\end{array}$ & $\begin{array}{c}0.392 \\
(0.384)\end{array}$ \\
\hline$D$ & - & 1 & $\begin{array}{c}0.151 \\
(0.746)\end{array}$ & $\begin{array}{c}0.345 \\
(0.448)\end{array}$ & - & 1 & $\begin{array}{c}-0.234 \\
(0.577)\end{array}$ & $\begin{array}{c}0.005 \\
(0.990)\end{array}$ & - & 1 & $\begin{array}{c}0.335 \\
(0.463)\end{array}$ & $\begin{array}{c}0.181 \\
(0.699)\end{array}$ \\
\hline$B_{i}$ & - & - & 1 & $\begin{array}{c}0.890 \\
\left(0.007^{* *}\right)\end{array}$ & - & - & 1 & $\begin{array}{c}0.867 \\
\left(0.005^{* *}\right)\end{array}$ & - & - & 1 & $\begin{array}{c}0.929 \\
\left(0.002^{* *}\right)\end{array}$ \\
\hline$\Delta S O_{i j}$ & - & - & - & 1 & - & - & - & 1 & - & - & - & 1 \\
\hline
\end{tabular}

括号内数字表示显著水平 $(P$ 值 $), * *$ 表示 $P<0.01$.

湖泊内浮游植物优势种主要为蓝、绿、硅藻, 不同时期生境条件的变迁可以导致各优势种对资源利用强 
度和幅度的改变, 同时物种对资源利用分化或发生生态位移动,引起生存适合度变化,造成生态位量度出现 较大差异, 从而增加了湖泊内藻类的动态复杂性. 氮、磷是浮游植物生长繁殖的重要营养盐, 也是常见的限 制性营养元素. 结冰初期与融冰期, 灰关联分析结果得出 $\mathrm{TP}$ 与 $\mathrm{NH}_{3}-\mathrm{N}$ 优势种密度关联系数分别在两个时期 均较高, 这是由于水体中作为优势藻种的蓝藻门优势度和密度此时相对较高, 对氮、磷营养盐的吸收相比其 他门类浮游植物更具有竞争力; 结冰期由于水结冰过程中对浮游植物和不同环境因子排斥程度不同, 影响 浮游植物分布的环境因子也发生变化. 南海湖特殊的地理位置、气候特征和水文地质条件, 使得它不仅具有 寒旱区湖泊的特点同时也具有城市小型湖泊的典型特征. 而城市小型湖泊对环境变化敏感, 易受到人类干 扰影响, 湖泊水体的生境及其时空变化较为复杂. 季节性冻融使得南海湖的生境条件在不同时期有所不同, 湖泊内的环境因子、内外源污染物的输人、原水 (黄河) 藻类群落以及藻类生理特性等诸多因素均可能发生 变化, 从而影响湖泊内浮游植物分布, 导致不同时期生态位差异较大. 冻融期南海湖浮游植物群落比较脆 弱,物种组成变化较大,仍处于演替的初、中期阶段.

\section{4 结论}

1) 研究期间共鉴定出浮游植物 67 种, 隶属 7 门 57 属, 以绿藻的种类数最多, 占 $40 \%$; 其次是硅藻占 $27 \%$; 蓝藻占 $19.5 \%$. 南海湖冻融期浮游植物群落结构为绿藻-硅藻一蓝藻型.

2 ) 全湖浮游植物细胞密度变化范围为 $5.60 \times 10^{6} \sim 18.90 \times 10^{6}$ cells/L, 在空间上呈现湖区边缘向湖心递增 的趋势; 影响浮游植物细胞密度的主要环境因子是 $\mathrm{pH}$.

3 ) 将生态位方法和灰关联分析法相结合能较好地描述南海湖浮游植物优势种的群落生态特征. 调查期 间鉴定的优势种中, 四尾栅藻是整个冻融过程中最稳定的主要优势种, 其生态位量度均优于其他优势藻种.

4 ) 融冰期各优势种的生态位重叠值均较低, 冻融期间属微小平裂藻与其他优势种之间的生态位重叠程 度最大.

\section{5 参考文献}

[ 1 ] Chai Y, Peng T, Guo K et al. Community characteristics of phytoplankton in Lake Changhu and relationships with environmental factors in the summer of 2012. Chinese Journal of Plant Ecology, 2014, 38(8): 857-867. [柴毅, 彭婷, 郭坤等. 2012 年夏季长湖浮游植物群落特征及其与环境因子的关系. 植物生态学报, 2014, 38(8) : 857-867.]

[ 2 ] Kireta AR, Reavie ED, Sgro GV et al. Planktonic and periphytic diatoms as indicators of stress on great rivers of the United States: Testing water quality and disturbance models. Ecological Indicators, 2012, 13(1) : 222-231.

[ 3 ] Gilichinsky DA. Permafrost model of extraterrestrial habitat//Horneck G, Baumstark-Khan C eds. Astrobiology: The quest for the conditions of life. Berlin: Springer, 2002: 125-142.

[ 4 ] Xia YF, Hu XD, Xu JX et al. Seasonal succession of phytoplankton functional group and assessment of water quality in Lake Taihu. J Lake Sci, 2019, 31(1) : 134-146. DOI: 10.18307/2019.0113. [夏莹霏, 胡晓东, 徐季雄等. 太湖浮游 植物功能群季节演替特征及水质评价. 湖泊科学, 2019, 31(1) : 134-146. $]$

[ 5 ] Zhou XQ. Microbial activity during litter decomposition as affected by seasonal freeze-thaw cycle in the subalpine/alpine forests of Western Sichuan[Dissertation]. Ya'an: Sichuan Agricultural University, 2011. [周晓庆. 季节性冻融对川西亚 高山/高山森林调落物分解过程中微生物活性的影响 [学位论文]. 雅安: 四川农业大学, 2011.]

[ 6 ] Liu RH, Chang B, Rong CY et al. Niche of main woody plant populations of pterocarya stenoptera community in riparian zone of Lijiang River, China. Chinese Journal of Applied Ecology, 2018, 29(12) : 3917-3926. [刘润红, 常斌, 荣春艳 等. 漓江河岸带枫杨群落主要木本植物种群生态位. 应用生态学报, 2018, 29(12) : 3917-3926.]

[ 7 ] Chen LT, Shi XD, Gao RM. Interspecificassociation and niche characteristics of Taxus chinensis var. mairei communities in Lingchuan, Shanxi. Plant Science Journal, 2016, 34(4) : 521-529. [陈龙涛, 石晓东, 高润梅. 山西陵川南方红豆杉 群落种间联结与生态位特征研究. 植物科学学报, 2016, 34(4) : 521-529.]

[ 8 ] Wei WD, Liu YH, Ma H et al. Freeze thaw action characteristics of shallow soil on degraded alpine meadow in the source region of Three Rivers. Journal of Ecology and Rural Environment, 2019, 35(3) : 352-359. [魏卫东, 刘育红, 马辉等. 三江源区退化高寒草甸浅层土壤冻融作用特征. 生态与农村环境学报, 2019, 35(3) : 352-359.]

[ 9 ] Zhang DL. The study on the effect of migration and transformation of soil nitrogen on shallow groundwater under freezing 
and thawing[Dissertation]. Changchun: Jilin University, 2015. [张迪龙. 冻融作用下土壤氮素的迁移转化对浅层地 下水的影响 [学位论文]. 长春: 吉林大学, 2015.]

[10] Jiang QH, Pan T, Li WP et al. Phytoplankton community characteristics and its relationship with water quality factors in Nanhai Lake in winter. Journal of Northeast Forestry University, 2019, 47(4): 71-75. [姜庆宏, 潘粀, 李卫平等. 南海 湖冬季浮游植物特征及与水质因子关系. 东北林业大学学报, 2019, 47(4): 71-75.]

[11] Miao CL. The research of Nanhai wetland of Inner Mongolia Baotou City protection and exploitation[Dissertation]. Yangling: Northwest A \& F University, 2008. [苗春林. 内蒙古包头市南海湿地保护与开发利用研究 [学位论文]. 杨凌: 西北农林科技大学, 2008.]

[12] Ma F, Yang JX, Wei L et al eds. Environmental microbial map. Beijing: China Environmental Science Press, 2010: 1-71. [马放, 杨基先, 魏利等. 环境微生物图谱. 北京: 中国环境科学出版社, 2010: 1-71.]

[13] Zhou FX, Chen JH eds. Freshwater microbial map. Beijing: Chemical Industry Press, 2005: 1-178. [周凤霞, 陈剑虹. 淡水型微生物图谱. 北京: 化学工业出版, 2005: 1-178.]

[14] Ministry of Environmental Protection of the People's Republic of China, Editorial Board of Water and Wastewater Monitoring and Analysis Methods eds. Water and Wastewater Monitoring and Analysis Methods: 4th edition. Beijing: China Environmental Science Press, 2002. [国家环境保护总局《水和废水监测分析方法》编委会. 水和废水监测分析方法: 第 4 版. 北京: 中国环境科学出版社, 2002.]

[15] Mcnaughton SJ. Relationship among functional prosperities of California grassland. Nature, 1967, 216: 168-169.

[16] Wu TH, Liu JS, Deng JM et al. Community structure of phytoplankton and bioassessment of water quality in a largewatercarrying lake, Lake Hongze. J Lake Sci, 2019, 31(2) : 440-448. DOI: 10.18307/2019.0213. [吴天浩, 刘劲松, 邓建 明等. 大型过水性湖泊——洪泽湖浮游植物群落结构及其水质生物评价. 湖泊科学, 2019, 31(2): 440-448.]

[17] Xu CY, Yu QJ, Xu FJ et al. Niche analysis of phytoplankton's dominant species in Dianshan Lake of East China. Chinese Journal of Applied Ecology, 2012, 23(9) : 2550-2558. [徐春燕, 俞秋佳, 徐凤洁等. 淀山湖浮游植物优势种生态位. 应用生态学报, 2012, 23(9): 2550-2558.]

[18] Xia T, Chen J, Cao FY et al. Niche analysis of phytoplankton in an urban river connected with the Yangze River, Zhenjiang, China. Resources and Environment in the Yangtze Basin, 2014, 23(3) : 344-350. [夏霆, 陈静, 曹方意等. 镇江 通江城市河道浮游植物优势种群生态位分析. 长江流域资源与环境, 2014, 23(3): 344-350.]

[19] Qin XB. Relationship between phytoplankton quantity and its environmental factors in wetland of coldregions in spring and summer based on the grey association analysis. South China Fisheries Science, 2009, 5(1): 17-22. [覃雪波. 基于灰色 关联的寒区湿地春夏季浮游植物数量与环境因子关系. 南方水产, 2009, 5(1): 17-22.]

[20] Jiao HF, Shi HX, You ZJ et al. Niche analysis of dominant species of macrobenthic community at a tidal flat of Yushan Island. Acta Ecologica Sinica, 2011, 31(14) : 3928-3936. [焦海峰, 施慧雄, 尤仲杰等. 渔山岛岩礁基质潮间带大型 底栖动物优势种生态位. 生态学报, 2011, 31(14): 3928-3936.]

[21] Guo K, Yang DG, Peng T et al. Ecological niche analysis of dominant species of phytoplankton in Lake Changhu, Hubei Province. J Lake Sci, 2016, 28(4) : 825-834. DOI: 10.18307/2016.0416. [ 郭坤, 杨德国, 彭婷等. 湖北省长湖浮游 植物优势种生态位分析. 湖泊科学, 2016, 28(4): 825-834.]

[22] Guo Y, Yang S, Shen YF et al. Composition and niche of the existing herbaceous plants in the water-level-fluctuating zone of the Three Gorges Reservoir Area, China. Chinese Journal of Applied Ecology, 2018, 29(11): 3559-3568. [ 郭燕, 杨 邵, 沈雅飞等. 三峡库区消落带现存草本植物组成与生态位. 应用生态学报, 2018, 29(11) : 3559-3568.]

[23] Du Y, Fan SQ, Zhang ZM. The variation of planktonic diatom in frozen and thawing periods in Hun river, Liao river and Taizi river. Chinese Journal of Forensic Medicine, 2014, 29(1): 30-32, 36. [杜宇, 㚞少群, 张子铭. 辽宁省主要河流 冰封期及开河后浮游硅藻变化规律. 中国法医学杂志, 2014, 29(1) : 30-32, 36.]

[24] Xiao X, Lou LP, Li H et al. Algal control ability of allelopathically active submerged macrophytes: A review. Chinese Journal of Applied Ecology, 2009, 20(3) : 705-712. [肖溪, 楼莉萍, 李华等. 沉水植物化感作用控藻能力评述. 应 用生态学报, 2009, 20(3): 705-712.]

[25] Spatharis S, Mouillot D, Chi TD et al. A niche-based modeling approach to phytoplankton community assembly rules. Oecologia, 2009, 159(1): 171-180.

[26] May RM. On the theory of niche overlap. Theoretical Population Biology, 1974, 5(3) : 297-332.

[27] Wang CH, Zhang JT. Niche analysis of diatoms in Fenhe river and Fenhe reservoir. Chinese Journal of Ecology, 2004, 
(3) : 58-62. [王翠红, 张金屯. 汾河水库及河道中优势硅藻生态位的研究. 生态学杂志, 2004, (3) : 58-62.]

[28] Fang T, He XR, Feng ZH et al. Ecological distribution and nutrient limitation of phytoplankton in adjacent sea of Guanhe Estuary in spring. Acta Ecologica Sinica, 2013, 33(15): 4567-4574. [方涛, 贺心然, 冯志华等. 灌河口邻近海域春 季浮游植物的生态分布及其营养盐限制. 生态学报, 2013, 33(15) : 4567-4574.]

[29] He R, Jiang R, Zhu XP et al. Seasonal variation of phytoplankton and its relationship with environmental factors in sea waters near Taishan. Chinese Journal of Ecology, 2018, 37(9): 2727-2736. [何瑞, 蒋然, 朱小平等. 台山附近海域浮游 植物的季节变化及其与环境因子的关系. 生态学杂志, 2018, 37(9) : 2727-2736.]

[30] Hu ZQ. Studies of the physiological ecological effects of microcystins on planktonic algae[Dissertation]. Wuhan: Institute of Hydrobiology, Chinese Academy of Science, 2004. [胡智泉. 微囊澡毒素对水华藻类的生理生态学效应研究 [学位 论文]. 武汉: 中国科学院水生生物研究所, 2004.]

[31] Wang XJ, Liu MX, Li SN et al. The effect of $\mathrm{CO}_{2}$ enrichment on elemental stoichiometry of phytoplankton under different trophic status. J Lake Sci, 2017, 29(6) : 1379-1385. DOI: 10.18307/2017.0610. [王秀娟, 刘米雪, 李胜男等. $\mathrm{CO}_{2}$ 浓 度升高对浮游藻类元素化学计量值的影响. 湖泊科学, 2017, 29(6) : 1379-1385.]

[32] Qiu XZ, Zhao HX, Sun XX. Studies on relationship of phytoplankton and water environmental factors in Shahu Lake. Environmental Science, 2012, 33(7) : 2265-2271. [邱小琮, 赵红雪, 孙晓雪. 宁夏沙湖浮游植物与水环境因子关系的 研究. 环境科学, 2012, 33(7) : 2265-2271.] 